\title{
DIFFICULT TO DIAGNOSE INTRAABDOMINAL TUMOR - PSEUDOMYXOMA PERITONEI
}

\author{
Ignatov V., K. Ivanov, N. Kolev, D. Hristov, A. Tonev, T. Temelkov \\ Department of General and operative Surgery, University Hospital "St. Marina" \\ Reviewed by: Assoc. Prof. R. Madjov, MD, PhD
}

\begin{abstract}
Pseudomyxoma peritonei (PMP) is a rare neoplastic, chronic and insufficient disease, which has the the charackteristics of the diseminated mucinous ascites and the presence of peritoneal implants. The making of precise and well-timed diagnosis is a difficult process because of the lack specific symptoms. The exact preoperative diagnosis 'PMP" can be prescribe after CT-imaging, which is sensitive with its 'mussel shell' symptom on the surface of the visceral organ, resulting from the compresion of the vicouse mucinous ascites and the presence of fibrosis. We report a rare case of our practice, with anamnesis of abdominal swelling, lost of apetite, consumative syndrome - more than $\mathbf{1 0}$ kilos for two months. The difficulties in diagnostic process were overhelmed. Despite of the quantity of the studies, directed to the treatment of PMP, this disease stay constantly enigmatic with prolongated clinical elapsing and the high level of recurrency in the complex treatment and have to be discussed the application of operative methods and chemotherapy
\end{abstract}

Pseudomyxoma peritonei (PMP) is a rare neoplastic, chronic and insufficient disease, which has the the charackteristics of the diseminated mucinous ascites and the presence of peritoneal implants. (1)

There are two different biological types, which have prolonged elapse and tendancy to be aggressive:

- Diseminated peritoneal adenomatosis (DPA)- binign type - Peritoneal mucinous carcinosis (PMC)- malignant type PMP is female-like tumor and is associated with the presence of ovarial mucinous tumor. It is very rare met in men, because of the other type of origin - lessions of the appendix!!!! Other possibile primary tumor sources could be lession in the rectum, colon, gall-bladder, pancreas, urachus, bladder, mammal gland, and lung, but they are very rare and are associated with peritoneal mucinous carcinosis (PMC) (2)

According Solkar et al. 2004, only $10 \%$ of the patients with PMP have 5.5 year survivul rate after the diagnosing. $(3,4)$ The making of precise and well-timed diagnosis is a difficult process because of the lack specific symptoms. The exact preoperative diagnosis 'PMP' can be prescribe after CT-imaging, which is sensitive with its 'mussel shell' symptom on the surface of the visceral organ, resulting from the compresion of the vicouse mucinous ascites and the presence of fibrosis. Due to this image method there often can be found multiple cystic masses with lipid consistency in the peritoneum. They could have ferrules of calcificates with typical festooning of the liver outlines, the thickness of the omentum, and the differences in the compression of visceral organs and structures. The preoperative ultrasound examination frequent shows raw, sluggish ascites with septal adhesions and high levels of ultrasound consistency. The combination of clinical results and radiological signs are highly specifing for the diagonsis of PMP. In patients with occasional find, radiology can find abdominal calcifacation plates, ascites and unseparated soft tissue masses. In this cases the method of choise is CT. (5)

The accuracy and specifity of MRI in the diagnostics is not clear yet.

The explorative diagnostic laparoscopy is indicated as gold standard in diagnosis-making and consequent morphological investigation.

A study of O'Connel J.T. et al. 2002 precensts PMP as neoplastic disease from MUC-2 producing goblet cells. The extracellular accumulation of mucin is due to alteration of glucoprotein in the cells extremitas in the tumor's stroma. (6) The most frequent operations are according to surgical treatment of PMP:

- Right Hemicolectomy- $88 \%$

- Resection of the sigma- $65 \%$

- Gastrectomy- $47 \%$

- Colectomy- 6\%

- Splenectomy- 79\%

- Cholecystectomy- $76 \%$

- Histerectomy and bilateral salpingo-ooforectomy 50\%

- Omentectomy- $60 \%$

(De Simone M, et al. 2006) (7)

The developing of treatment strategy in cases of PMP is a discutable question, yet. Complex therapy is applied, including citoreductive surgical procedure and segmentary resection the obturated organ and omentectomy. Reoperation is necessary in the cases of recidives.

In a study of Sugarbaker et al. 1995, they proved that intraoperative chemotherapy with 5-fluorouracil and Mythomicyn C have minimal effect in the reduction of "tumor implants" of atypical epithelium and don't provoke apopthosis of these cells. (8)

Deraco et al. 2006 make resection of mainly engaged organ and intraoperituneal citoreductive chemotherapy with 
Mythomicyn C, warmed up to $42^{\circ} \mathrm{C}$. (9) The aim is to be removed the tumor "in toto" and to be destroyed the residual small tumor nodes, according to Smeenk et al. 2006. They notice that the conducting of combined therapy, despite of high levels of toxicity, enlarge the survival rate. (10) Miner J.T. et al. 2005 defined that the prognosis of the outcome is connected with :

- Tumor diferentiation (G) - morphologically confirmed.

- Preoperative extend of the tumor

- The resection of the targeted organ and citoreductive therapy. (11)

The most informative carcino markers are CEA and CA-19-9, which are increasing their levels in case of recidive. (12)

According to Sugarbaker et al. 1995, it is necessary to be applied chemotherapy with 5fluorouracil + Mythomicyn C with "Second look" when are made big operations with grate extend of the surgery. The tumor markers have to be investigated in a 3 month period CT have to be made in a 6 month period. (8)

Deraco et al. 2003 classify the disease in four grade scale, according to followed criteria for mortality and morbidity:

- I. Grade - without complications

- II. Grade - small and light complications

- III. Grade - serious complications (demanding reoperation and intensive care)

- IV. Grade - in status that led to exitus letalis (13)

\section{RESULTS}

We present a case of PMP, a male on 53 years, who enter in the Clinic of General and Operative Surgery with anamnesis of abdominal swelling, lost of apetite, consumative syndrome - more than 10 kilos for two months and laboratory data as presented:

\begin{tabular}{||c|c||}
\hline \hline Hct & 0,35 \\
\hline Leu & 6,3 \\
\hline CУE & 94 \\
\hline CEA & 17,3 \\
\hline CA19-9 & 1257 \\
\hline Protein & 75 \\
\hline Albumin & 36 \\
\hline Urea & 3,8 \\
\hline Glucose & 4,3 \\
\hline \hline
\end{tabular}

By the applied abdominal ultrasonography we found a presence of moderate qantity of ascites, which fluctuated with ultrasonogenic structures and fixated intestinal stitches to the liver and diaphragma. We evacuate yellow ascites, which gelatinize as soon as it was get out of the body. The CT data showed us plenty of cystic lesions in the perito- neum, which were compressed the liver. The liver had a typical festoon image. The consistency of the ascites was about $20 \mathrm{HE}$. We found hevily thicked omentum majos and clinical view as PMP Through the exploration of the abdominal cavity in planned order, we found plenty brids between abdominal organs, yellow-like jelly ascites around 2 1 (includes many light formation)

We found intact appendix, which was situated medial and retrperitoneal. The omentum was enveloped by the tumor formation with extends of 15/10/5 cm. (Fig. 1 - 7)
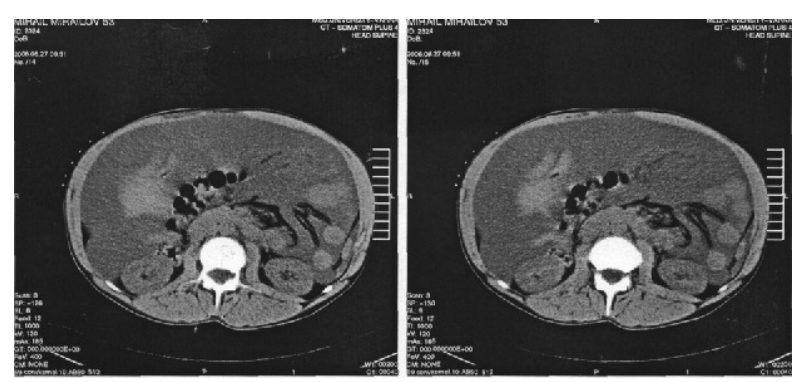

Fig. 1.
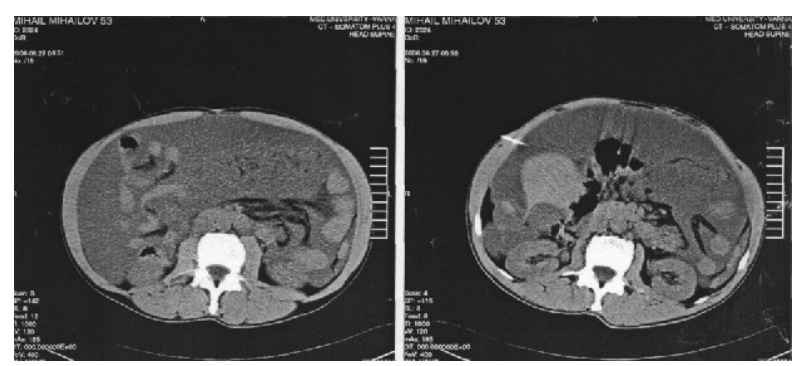

Fig. 2.

Omentectomia and lavage was made by serum phisiologicum. At last, we put two drainages.

The early postoperative period was smooth, under the protection analgetics, cristaloid solutions, monosaccharids solutions and low-weight heparins.

Morphologiacally investigated materials were introduced by multiple necrosis and confluated mucous tracts, separated by different in size septal brids with hyperfolicular vessels and lymphotic infiltrats. Morphological diagnosis: Pseudomyxoma peritonei.

The patient was directed for initiating of systematic chemotherapy with Mythomicyn C and 5-fluorouracil.

\section{CONCLUSION}

Despite of the quantity of the studies, directed to the treatment of PMP, this disease stay constantly enigmatic with prolongated clinical elapsing and the high level of recurrency in the complex treatment and have to be discussed the application of operative methods and chemotherapy. 


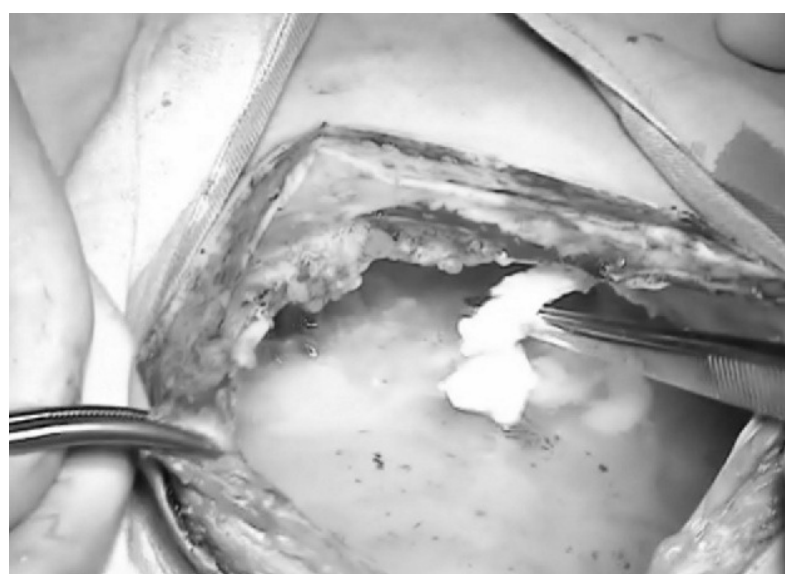

Fig. 3.

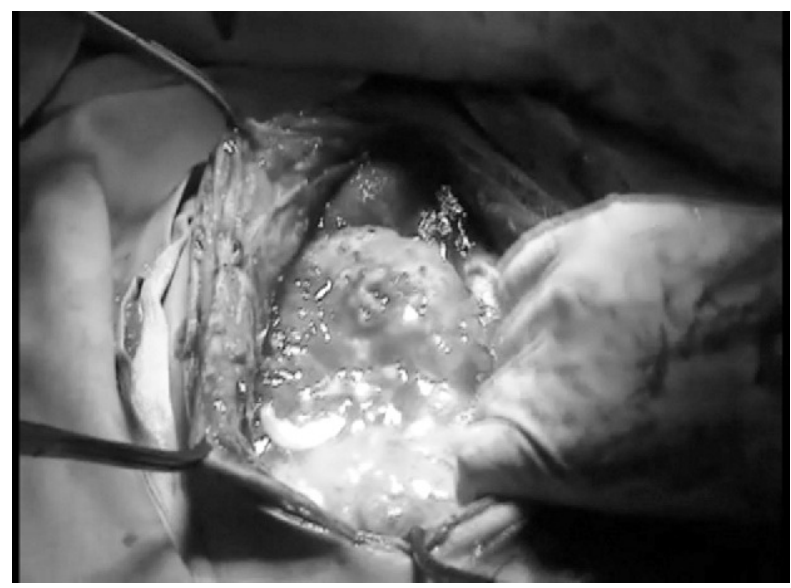

Fig. 4.

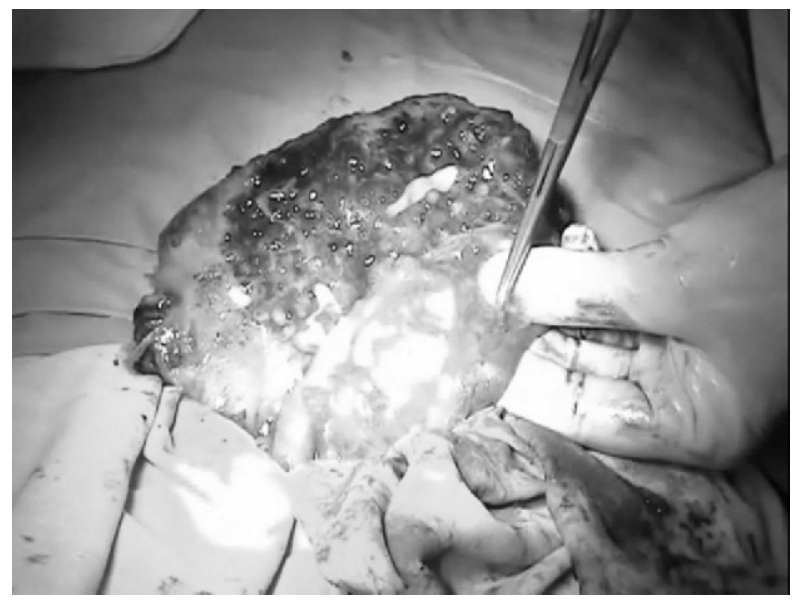

Fig. 5.

\section{REFERENCES}

1. Fann JI, Vierra M, Fisher D, Oberhelman HA Jr, Cobb L. Pseudomyxoma peritonei. Surg Gynecol Obstet. 1993 Nov;177(5):441-7.

2. Galani E, Marx GM, Steer CB, Culora G, Harper PG. Pseudomyxoma peritonei: the 'controversial' disease. Int J Gynecol Cancer. 2003 Jul-Aug; 13(4):413-8.

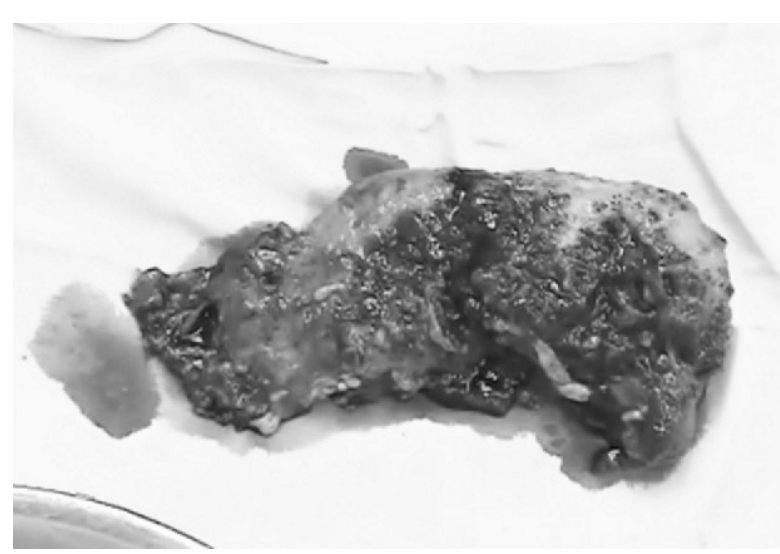

Fig. 6.

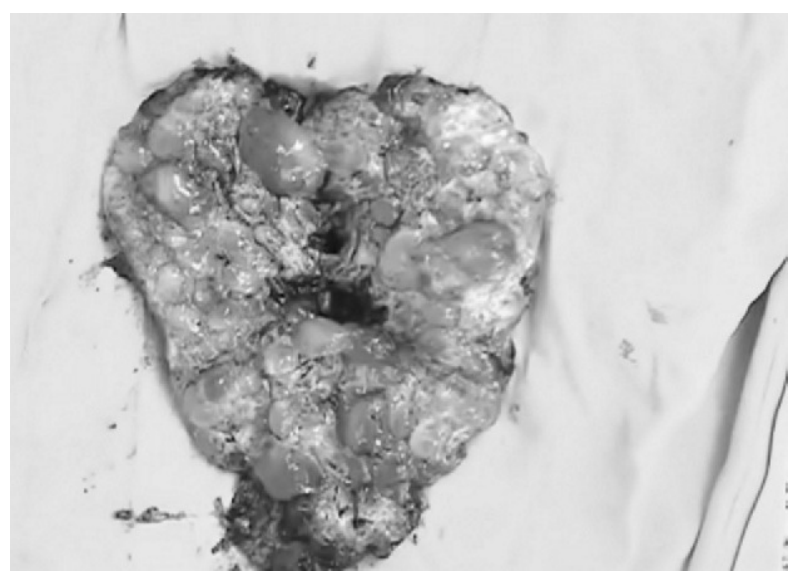

Fig. 7.

3. Solkar MH, Akhtar NM, Khan Z, Parker MC. Pseudomyxoma extraperitonei occurring 35 years after appendicectomy: a case report and review of literature World J Surg Oncol. 2004 Jun 4;2(1):19.

4. Solkar MH, Khan MZ, Parker MC. Pseudomyxoma peritonei confined to the retroperitoneum occurring 35 years after appendicectomy. Int J Colorectal Dis. 2004 Jul; 19(4): 399-400. Epub 2004 Apr 9.

5. Hossain J, Malabarey T, al-Mofleh I, Hawass $\mathrm{NE}$, Ismail AH. Clinical and radiological features of pseudomyxoma peritonei. J R Soc Med. 1989 Oct; 82(10):600-2.

6. O'Connell JT, Hacker CM, Barsky SH. Pseudomyxoma peritonei is a disease of MUC2-expressing goblet cells. Am J Pathol. 2002 Aug; 161(2): 551-64.

7. De Simone M, Vaira M, Caponi A, Ciaccio B, Fiorentini G, Turrisi G, Ferri L, Buti G. Ten years experience in the treatment of pseudomyxoma peritonei by cytoreduction, peritonectomy and semi-closed hyperthermic antiblastic peritoneal perfusion. In Vivo. 2006 Nov-Dec; 20(6A):725-7.

8. Sugarbaker PH. Pseudomyxoma peritonei. A cancer whose biology is characterized by a redistribution phenomenon Ann Surg. 1994 Feb; 219(2):109-11.

9. Deraco M, Kusamura S, Laterza B, Favaro M, Fumagalli L, Costanzo P, Baratti D. 
Cytoreductive surgery and hyperthermic intra-peritoneal chemotherapy (HIPEC) in the treatment of pseudomyxoma peritonei: ten years experience in a single center. In Vivo. 2006 Nov-Dec; 20(6A): 773-6.

10. Smeenk RM, Verwaal VJ, Zoetmulder FA. Pseudomyxoma peritonei. Cancer Treat Rev. 2006 Dec 18; In print

11. Miner TJ, Shia J, Jaques DP, Klimstra DS, Brennan MF, Coit DG. Long-term survival following treatment of pseudomyxoma peritonei: an analysis of surgical therapy. Ann Surg. 2005 Feb; 241(2):300-8.
12. Carmignani $\mathrm{CP}$, Hampton $\mathrm{R}$, Sugarbaker $\mathrm{CE}$, Chang D, Sugarbaker PH. Utility of CEA and CA 19-9 tumor markers in diagnosis and prognostic assessment of mucinous epithelial cancers of the appendix J Surg Oncol. 2004 Sep 15;87(4):162-6.

13. Deraco M, Gronchi A, Mazzaferro V, Inglese MG, Pennacchioli E, Kusamura S, Rizzi M, Anselmi RA Jr, Vaglini M. Feasibility of peritonectomy associated with intraperitoneal hyperthermic perfusion in patients with Pseudomyxoma peritonei Tumori. 2002 Sep-Oct; 88(5):370-5. 